\title{
AC 2011-2522: INTEGRATING ADAPTED PHYSICAL ACTIVITY PROJECTS INTO A COMPUTER ENGINEERING CAPSTONE CLASS
}

\author{
Lynne A Slivovsky, California Polytechnic State University
}

Lynne A. Slivovsky, Associate Professor of Electrical and Computer Engineering (Ph.D., Purdue University, 2001), has led service-learning initiatives both within the College of Engineering and across the university at California Polytechnic State University, San Luis Obispo. In 2003 she received the Frontiers In Education New Faculty Fellow Award. Her work in service-learning led to her selection in 2007 as a California Campus Compact-Carnegie Foundation for the Advancement of Teaching Faculty Fellow for Service-Learning for Political Engagement. She currently oversees two multidisciplinary service-learning programs: the Access by Design project that has capstone students design devices for people with disabilities to participate in adapted physical activity and Organic Twittering that merges social media with sustainability.

\section{Dr. James M Widmann, California Polytechnic State University}

Jim Widmann is a Professor of Mechanical Engineering at California Polytechnic State University, San Luis Obispo. He received his Ph.D. in 1994 from Stanford University. Currently he teaches mechanics and design courses. He conducts research in the areas of design optimization, machine design, fluid power control and engineering education.

\section{Dr. Brian P. Self, California Polytechnic State University}

Brian Self is a Professor in the Mechanical Engineering Department at California Polytechnic State University in San Luis Obispo. Prior to joining the faculty at Cal Poly in 2006, he taught for seven years at the United States Air Force Academy and worked for four years in the Air Force Research Laboratories. Research interests include active learning and engineering education, spatial disorientation, rehabilitation engineering, sports biomechanics, and aerospace physiology. He worked on a team that developed the Dynamics Concept Inventory and is currently collaborating on a grant to develop and assess Model Eliciting Activities in engineering. Brian was the 2008-2010 ASEE Zone IV Chair and serves as Cal Poly's ASEE Campus Representative.

\section{Prof. J.Kevin Taylor, Cal Poly, San Luis Obispo}

J. Kevin Taylor is a Professor of Kinesiology at California Polytechnic State University, San Luis Obispo. He received a Ph.D. in Eduction from the University of South Carolina (1994), with specialization in Physical Education Teacher Education. Professor Taylor has been teaching Adapted Physical Activity for twelve years with a heavy emphasis on service-learning, he and his students run physical activity programs for the local community of people with disabilities. For the past eight years he has been collaborating with colleagues in engineering to design and build adaptations that facilitate inclusion of people with disabilities in physical activity. 
Integrating Adapted Physical Activity Projects into a Computer Engineering Capstone Class

7
$\mathbb{D}$
0
0
$N$
$N$
$\infty$
0
0
N 


\begin{abstract}
The capstone design class is the culmination and synthesis of a student's undergraduate experience. It plays a key role in many institutions' accreditation processes and its importance cannot be understated. In the class, topics such as universal design, user-centered design, needs analysis, requirements specification, validation, teamwork, and communication skills are common across disciplines and across universities. Projects may be devised by a collective group of faculty, sponsored by industry, extend from research projects, or, in the case of servicelearning, may serve the needs of non-profit community partners. Though the project genres vary, the intended learning outcomes drive the student experience. The Computer Engineering program at California Polytechnic State University, San Luis Obispo has a two-quarter capstone design class that guides students through the design process to address open-ended problems for real-world clients. A significant percentage of these projects are for the design of assistive devices for people with disabilities to participate in a variety of recreational activities. The endusers of these devices are given opportunities to exercise and experience greater independence through the devices designed by students in the class. This paper presents the design of the capstone class and the intent behind the in-class activities and out-of-class assignments that guide students through the design process.
\end{abstract}

\title{
Background
}

Service-learning occurs when "Students engage in community service activities with intentional academic and learning goals and opportunities for reflection that connect to their academic discipline" (Cress et al, 2005) ${ }^{1}$. It has been shown to be one of ten high-impact (i.e., those that provide for deep learning) "educationally purposeful activity" ${ }^{2,3}$. The reflection aspect of service-learning is an integral part of that deeper learning and helps to develop critical thinking

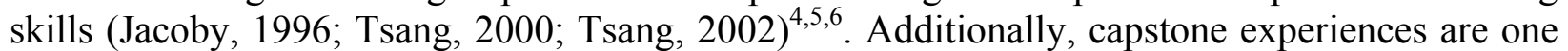
of these educationally purposeful activities ${ }^{2,3}$. Here, we present the design and impact of a twoquarter computer engineering capstone sequence in which students design and build devices for people with disabilities to participate in physical activity.

Over the past five years, California Polytechnic State University (Cal Poly) has developed a strong partnership with the Central Coast Assistive Technology Center (CCATC). The Collaboration between Cal Poly and CCATC began with the development of the Cal Poly Adapted Paddling program (Figure 1). As part of their Adapted Physical Activity Program, the Kinesiology Department has made kayaking in a local bay accessible to over 40 community participants who are diagnosed with differing levels of spinal cord injuries. Paddlers have found the freedom of an aquatic environment to be very empowering. Similar benefits have been obtained through the EyeCycle program, where people who are blind or visually impaired ride tandem bicycles. Kinesiology students take the "captain's" position while participants sit in the "stoker" position. A third part of the Kinesiology Adapted Activity Program is the Friday Club. This is a Special Olympics program that brings people with developmental disabilities to the Cal Poly campus to learn a variety of sports skills. The Adapted Physical Activity Programs have generated several collaborative efforts between CCATC, the Mechanical Engineering (ME) Department, and the Kinesiology Department. 


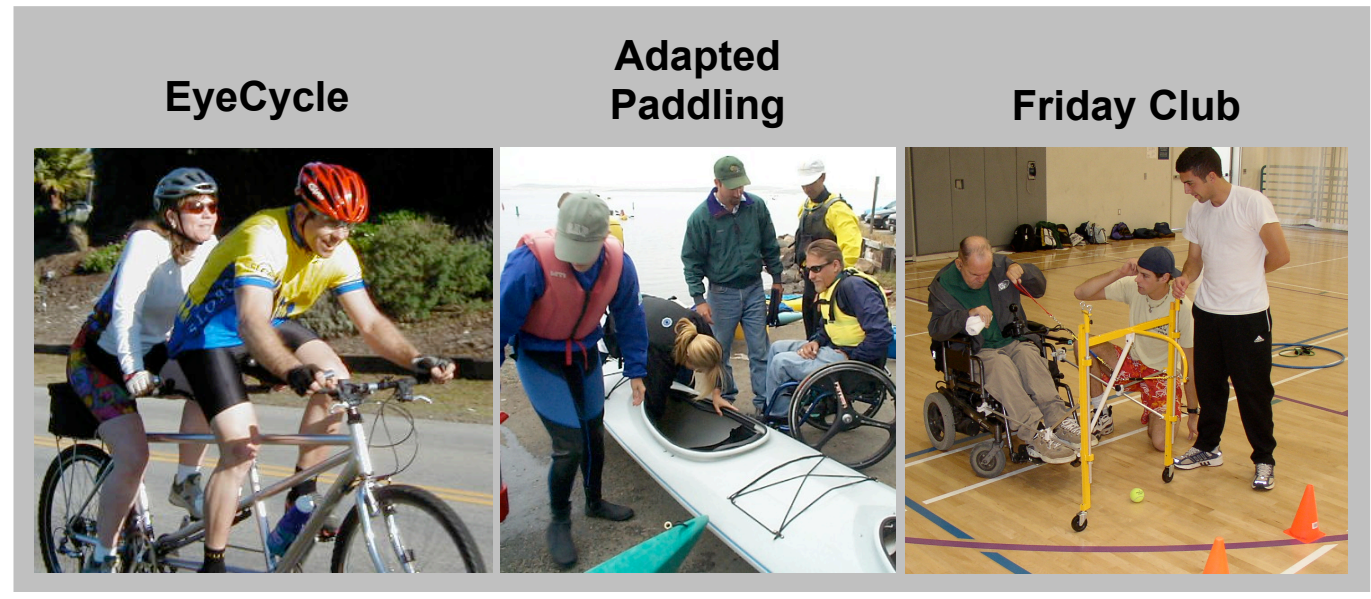

Figure 1. Adapted Physical Activity Programs.

\section{Capstone Service-Learning Example Project Descriptions}

During the past two years, approximately nine teams of computer engineering students have completed or are in the process of designing and building capstone design projects whose goals are to increase recreational access to persons with a variety of disabilities (predominantly for people with physical disabilities or for people who are blind). Two team projects are highlighted below to provide examples for the scope and complexity of typical adapted physical activity projects. Additional ongoing projects include Wii-B-Fit (an adapted Wii gaming system for people with physical disabilities) and the Untethered Runner (a system for people who are legally blind to run independently without a physical tether or sighted guide).

\section{SoloQuad Kayak Conversion Control System}

The SoloQuad Conversion Project (Figures 2 and 3) was an ongoing project that has been significantly enhanced through inclusion in the RAPD grant. The SoloQuad Conversion Project began in 2003 with the award of a "Quality of Life Grant" from the Christopher and Dana Reeve Foundation and was the first collaboration between Kinesiology and Engineering to focus on student design projects to facilitate participation in recreation. The project goal was to give independent control over a kayak to someone with high-level quadriplegia. This was done by adding an electric motor to the kayak and providing control over the motor using a joystick to pilot the craft. It has since undergone a number of prototypes and design revisions on the stability, seating, and control subsystems. Ultimately the SoloQuad Conversion Project will be utilized by the Cal Poly Adapted Paddling Program to provide opportunities to kayak for local community members with quadriplegia. 


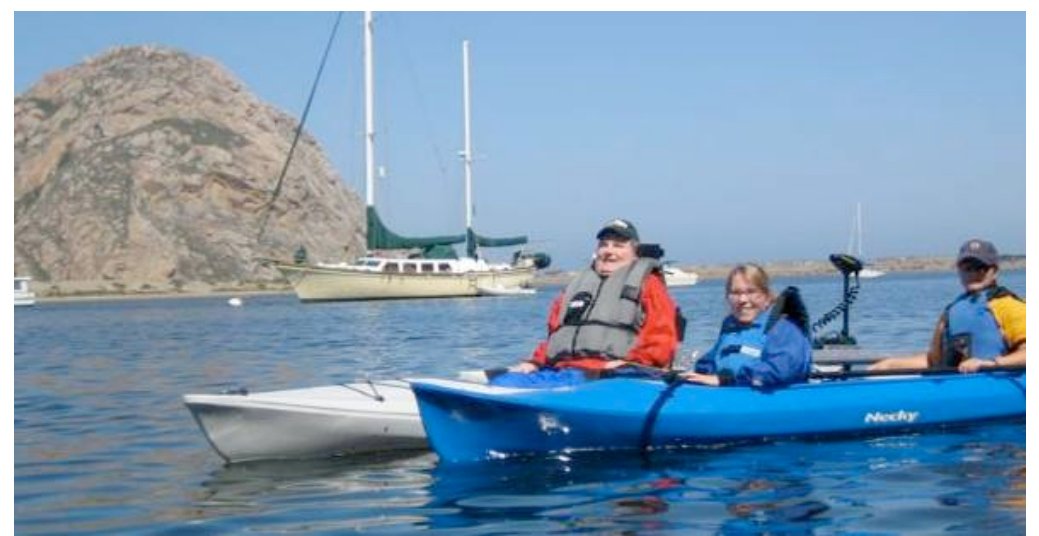

Figure 2. Solo-Quad Kayak for paddlers with high level quadriplegia.

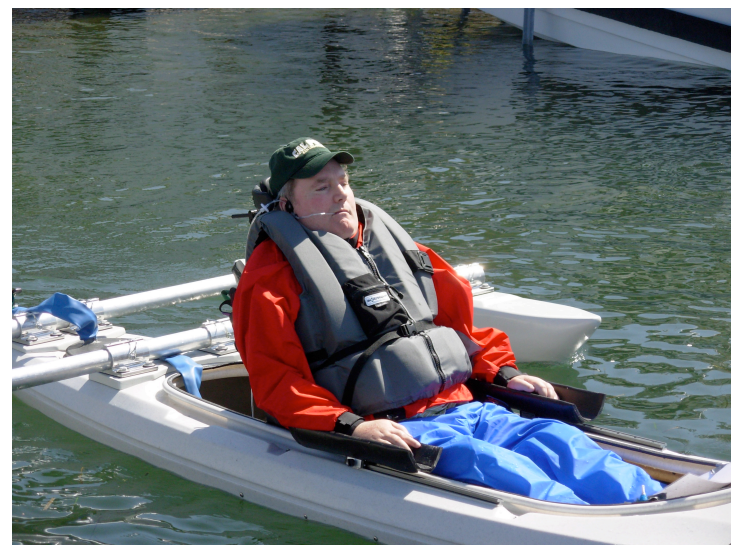

Figure 3: The SoloQuad Kayak is controlled (forward and backward speed, left and right steering) by the kayaker using a sip-and-puff device.

The main focus of this stage of the SoloQuad Conversion Project was to redesign the subsystem that controls the motor and to provide multiple user input devices for people with different abilities.

The requirements for the project were as follows:

- The system must be durable,

- The system must be able to be used by people with various capabilities,

- The system must be able to operate for long periods of time,

- The system must be intuitive and designed for an operator that is not technically inclined,

- The system must be self inclusive and not require any external dependencies,

- The system must minimally detract from the original kayaking experience,

- The user must be able to have four directions of control (forwards, backwards, left, and right),

- The user must be able to determine when the power supply is nearly exhausted,

- The system must be safe for the user. 
The motor control system consists of an input device, an I/O board to monitor the device input, and a controller board that converts the device input to signals that are sent to the trolling motor. Infrared sensors are located on the motor shaft to provide feedback of the motor position to the controller board.

A fundamental principle of adaptation for people with disabilities is to adapt for congruence, meaning the adaptation should blend in as much as possible with the original equipment.

Additionally, the SoloQuad kayak was designed to be ability-appropriate, meaning that there are input devices (e.g., a joystick and a sip-n-puff controller) to match anybody's ability. On May 16, 2008, the SoloQuad Conversion Project completed its maiden voyage. The pilot (Figure 4), someone with high-level quadriplegia, was able to navigate the waters of Morro Bay for the first time in 25 years and described the experience as breathtaking.

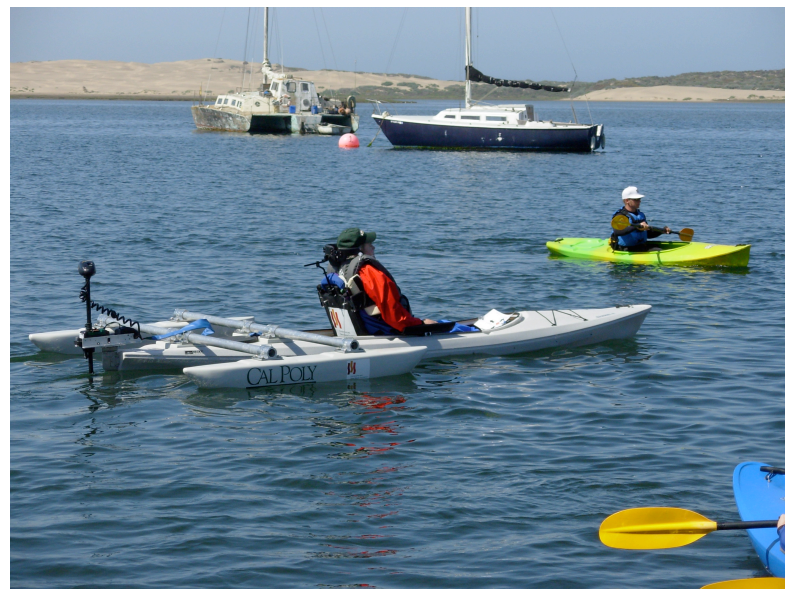

Figure 4: The SoloQuad pilot, someone with high-level quadriplegia, kayaks around Morro Bay.

\section{SoloQuad Kayak Conversion Project II}

The objective of this project was to improve performance and durability of the control system of the Solo-Quad Adaptive Kayak (Figure 4). The control system is modularized, allowing an individual with limited technical knowledge the ability to maintain and replace parts. The system is more rugged, being able to withstand the conditions of a turbulent marine environment, such as salt water, wind, and varying weather conditions. The system is more accurate than previous versions by allowing users to have finer control in steering with various ability-specific control devices.

The main board is the center of the kayak control system (Figure 5). It takes the control signals from a daughter board and uses them to set the direction and speed of the trolling motor. In addition, feedback of the motor from the motor control/feedback module is used to adjust motor speed and direction. This board is also responsible for power regulation and distribution to other functional modules. Inputs include the $12 \mathrm{~V}$ power from the car battery, the motor feedback from the motor control/feedback module, the control signal from the daughter board, and the reset and 
power buttons. Outputs include $5 \mathrm{~V}$ power to the daughter board and motor control/feedback modules, directional control and PWM output voltage to the motor, and status to the user.

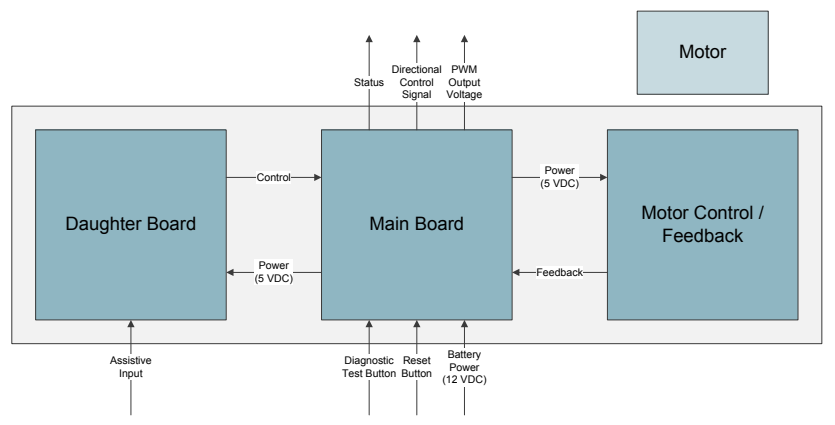

Figure 5: Overall system architecture.

The daughter board takes the signal from the assistive device (joystick, Sip ' $n$ ' Puff, or chin joystick) and converts it to the game port protocol used by the microcontroller on the main board. Its inputs are $5 \mathrm{~V}$ power distributed from the main board and the assistive device signal. Output is the converted control signal from the assistive device to the main board via the universal controller port. There is a daughter board for each assistive device that doesn't follow the protocol of the 15-pin game port. For example, the joystick can be connected directly to the main board while the Sip 'n' Puff device requires a daughter board.

The motor control/feedback module detects the current location of the motor shaft and speed of the motor, which it sends back to the main board. The motor is not part of the module, but rather the motor control/feedback module detects the direction of the motor. Speed and direction is adjusted by the direction control signal and PWM output voltage from the main board. The motor control/feedback module merely detects the position and speed of the motor and relays the information back to the main board. Input is $5 \mathrm{~V}$ power from the main board and output is the feedback signal to the main board (Figure 6).

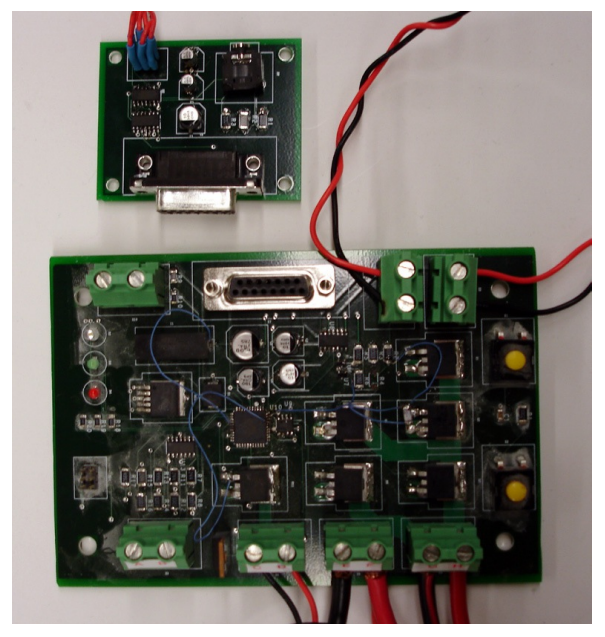

Figure 6: The new printed circuit board (PCB) versions of the Motor Control and I/O Boards include some design modifications. 


\section{Computer Engineering Capstone Course Structure}

The capstone design class in Computer Engineering has an annual enrollment of approximately 60 students and 12 projects/year, typically performed by teams of five students. Out of all projects, over $50 \%$ are designed for non-profit community partners and the remaining projects are split between industry and faculty sponsorship. All students are presented with a typical design process to guide them through their projects.

The basic design process followed in all classes consists of:

- A project definition phase where students develop a list of requirements in conjunction with their sponsor to insure that the problem is fully understood and the user needs will be addressed in the design.

- A conceptual design phase where students creatively explore as many solutions to the given design task as possible.

- A concept selection phase where different ideas are evaluated and the best concepts are selected for detail design.

- A detail design phase where standard components are selected, detailed analysis occurs and drawings, schematics and software structures are created.

- A manufacturing phase where raw materials and standard parts are procured, custom parts produced, electronic circuits assembled and software created.

- A testing phase in which design requirements are verified and necessary modifications are made.

Deliverables coinciding with the design phases include a Project Charter, a Design Report and Critical Design Presentation and Review with the project sponsor, a formal Test Plan, a Final Project Report and a hardware demonstration at the annual Senior Design Expo. These design artifacts and a number of in- and out-of-class assignments have been crafted to meet the learning objectives for the course:

1. Articulate design specifications and criteria by which they are to be measured.

2. Design and defend a solution to a real-world problem.

3. Verify that a design implementation to solve a real-world problem satisfies all specified project requirements, such as marketing, engineering, and constraints.

4. Evaluate the effectiveness of one's own team and other teams' designs.

5. Effectively contribute one's own disciplinary knowledge on a team as well as locate and evaluate new information.

6. Contribute to effective project management (e.g., through the use of Gantt charts).

7. Effectively communicate with others in a team, fulfilling one's individual role in the project and in interfacing with customers.

8. Employ principles of effective communication.

9. Employ ethical practices in all aspects of the design process.

10. Reflect on aspects of design and the design process. 
For many students who are beginning the capstone design class, this is their first significant design experience. As such, the first quarter of the capstone is more structured than the second and focuses on building individual design skills as well as team development. The second quarter focuses on implementation and testing. Table 1 details the variety and intent of assignments and activities throughout the two quarters.

Table 1: Intentional activities to address capstone learning objectives.

Quarter 1

\begin{tabular}{|l|l|}
\hline Activity & Primary Intent \\
\hline $\begin{array}{l}\text { Floating-Sinking Device - design a device that sinks after 5 } \\
\text { seconds, remains on the bottom for at least 5 seconds, and then } \\
\text { floats back to the surface. }\end{array}$ & Team development \\
\hline $\begin{array}{l}\text { Observation - What we want you to do in preparation for the first } \\
\text { phase of the design process is to consider your own ability to observe } \\
\text { and perceive, which is part of learning. You will do this by actively } \\
\text { observing people around campus in class today. }\end{array}$ & Design skill building \\
\hline $\begin{array}{l}\text { Team Logo Design - Design a team logo that best represents your } \\
\text { team members and its project using the Nominal Group Technique }\end{array}$ & Design skill building \\
\hline Creativity - materialize an intent using matches and glue & Design skill building \\
\hline $\begin{array}{l}\text { Legos - Duplicate the complicated Lego structure in the hall } \\
\text { without touching any pieces. }\end{array}$ & Team development \\
\hline Personas - Develop personas for your project. & Design skill building \\
\hline $\begin{array}{l}\text { Reflections - \#1 how you view yourself as a designer (at the start } \\
\text { of the project), \#2 assumptions about your client. }\end{array}$ & Individual \\
\hline
\end{tabular}

Quarter 2

\begin{tabular}{|l|l|}
\hline Activity & Primary Intent \\
\hline $\begin{array}{l}\text { Reflections - \#1 teamwork, \#2 how you view yourself as a } \\
\text { designer (at the end of the project) }\end{array}$ & Individual \\
\hline $\begin{array}{l}\text { Test Plan - Develop a test plan that ties back to your } \\
\text { requirements. }\end{array}$ & Design skill building \\
\hline
\end{tabular}

\section{Assessment of Learning}

A variety of tools are being used to assess the student outcomes in terms of the course goals as well as student attitudes about persons with disabilities. The assessment of the capstone design learning outcomes is accomplished through traditional means such as the quality of technical reports and presentations. We are also collecting student-completed pre- and post-surveys to measure gains in student attitudes toward people with disabilities, motivation, and design efficacy. Specifically we are interested in how engineering students view people with disabilities and how the service learning experience might change that. Analysis of this data is ongoing. 


\section{Conclusion}

It is evident that service-based design projects that improve the lives of people with disabilities can provide a platform for attainment of the diverse set of learning objectives and student outcomes expected of capstone design classes. It is our intent to compare how students might benefit to a greater or lesser extent based on whether their project is an adapted physical recreation project versus more traditional industrial projects. Preliminary evidence points to the fact that students may feel more highly motivated and develop a greater sense of the roles that engineers play for the good of society. This may be due to the immediate feedback they receive by working directly with their end-users.

\section{Acknowledgements}

The authors gratefully acknowledge the financial support of the National Science Foundation under award CBET-0756210.

\section{References}

1. Cress, C.M., Collier, P.J., and Reitenauer, V.L. (2005) Learning Through Serving: A Student Guidebook for Service-Learning Across the Disciplines. Stylus Publishing, Sterling, VA.

2. Jayne E. Brownell and Lynn E. Swaner (2010). Five High-Impact Practices: Research on Learning Outcomes, Completion, and Quality. American association of Colleges and Universities.

3. George D. Kuh. (2008). High-Impact Educational Practices: What They Are, Who Has Access to Them, and Why They Matter. American association of Colleges and Universities.

4. Jacoby, B. (1996) "Service-Learning in Today's Higher Education", in Service-Learning in Higher Education: Concepts and Practices, ed. B. Jacoby and Associates, Jossey-Bass Publishers, San Francisco, CA.

5. Tsang, E. (2000). Service Learning: A Positive Approach to Teaching Engineering Ethics and Social Impact of Technology. Proceedings of the 2000 ASEE Annual Conference \& Exposition, St. Louis, MO, June 18-21, 2000, Session 3630.

6. Tsang, E. (2002). Use Assessment to Develop Service-Learning Reflection Course Materials. Proceedings of the $32^{\text {nd }}$ ASEE/IEEE Frontiers in Education Conference, Boston, MA, Nov. 6-9, 2002, Session F2A. 